\title{
A de novo SEMA6B variant in a Chinese patient with progressive myoclonic epilepsy-11 and review of the literature
}

\author{
Qian Li \\ Soochow University Affiliated Children's Hospital \\ Min Liu ( $\square$ liuminroye@163.com ) \\ Dan-ping Huang \\ Soochow University Affiliated Children's Hospital \\ Tao Li \\ Soochow University Affiliated Children's Hospital \\ Jing Huang \\ Soochow University Affiliated Children's Hospital \\ Ping Jiang \\ Soochow University Affiliated Children's Hospital \\ Wei-hao Ling \\ Soochow University Affiliated Children's Hospital \\ Xuqin Chen \\ Soochow University Affiliated Children's Hospital
}

Soochow University Affiliated Children's Hospital https://orcid.org/0000-0002-5384-3672

\section{Research Article}

Keywords: SEMA6B, progressive myoclonic epilepsy, exome sequencing, gene curation

Posted Date: March 31st, 2021

DOI: https://doi.org/10.21203/rs.3.rs-306316/v1

License: @) (7) This work is licensed under a Creative Commons Attribution 4.0 International License. Read Full License 


\begin{abstract}
Progressive myoclonic epilepsy is a group of neurodegenerative diseases with complex clinical and genetic heterogeneity, which is associated with spontaneous or action-induced myoclonus and progressive neurodegeneration. Since 2020, 4 families with progressive myoclonic epilepsy-11 [OMIM\#618876] have been reported with a very limited spectrum of SEMA6B pathogenic variants. In our study, whole-exome sequencing was used in a proband from a nonconsanguineous Chinese family presenting with growth retardation and recurrent atonic seizures. A deletion mutation (c.1960_1978del, p.Leu654Argfs*25) in the last exon of SEMA6B was detected, which is a de Novo variant and pathogenic. The new genetic evidence we reported here strengthened the gene-disease relationship, and the gene curation level between SEMA6B and progressive myoclonic epilepsy-11 became "strong" following the ClinGen SOP. Therefore, the results of this study broaden the mutation spectrum of SEMA6B in different ethnic groups and strengthen the gene-disease relationship between SEMA6B and progressive myoclonic epilepsy-11.
\end{abstract}

\title{
Introduction
}

Progressive myoclonic epilepsy (EPM) is a group of neurodegenerative diseases with complex clinical and genetic heterogeneity that is associated with spontaneous or action-induced myoclonus and progressive neurodegeneration (Dijk and Tijssen 2010; Satishchandra and Sinha 2010; Franceschetti et al. 2014; Kälviäinen 2015; Malek et al. 2015). Neurological deterioration may include neuropathy, ataxia, progressive cognitive decline and myopathy. Although myoclonic seizures are a core feature, other types of seizures occur frequently, including generalized tonic-clonic, tonic and atypical absence seizures. Other types of epilepsy are often more problematic than myoclonic seizures (Holmes 2020).

Most of the diseases are inherited in an autosomal-recessive manner, and a few show autosomal-dominant inheritance or mitochondrial inheritance. In some patients with EPM, the etiology cannot be determined. However, in recent years, with the development of molecular genetics techniques, especially the clinical application of second-generation sequencing technology, it has been found that mutations in many genes (such as GOSR2, ASAH1, KCND7, TBC1D24, SCARB2, PRICKLE1, CARS2, SERPINI) can lead to EPM. Very limited case reports have shown that pathogenic variants in semaphorin 6B (SEMA6B) can also cause progressive myoclonic epilepsy-11 [EPM-11; OMIM\#618876]. Hamanaka et al found three de novo heterozygous frameshift mutations in the last exon of the SEMA6B gene that occurred in four patients from four independent families(Hamanaka et al. 2020), and none in Chinese patients so far. The narrow mutation spectrum of SEMA6B in patients with progressive myoclonic epilepsy has limited our understanding of the relationship between SEMA6B and this disease.

Here, we report a Chinese girl with a de novo mutation in SEMA6B who presented with growth retardation and recurrent atonic seizures, as well as abnormal electroencephalogram (EEG) waves; thus, the gene (SEMA6B)-disease (EPM) relationship was "moderate" according to the ClinGen gene curation protocol. The reporting of this case elevates the level of gene-disease association from "moderate" to "strong", thus further strengthening the causal relationship between SEMA6B and EPM-11.

\section{Materials And Methods Participants}

A nonconsanguineous Chinese family including a EPM-11 sufferer was recruited at Children's Hospital Affiliated to Soochow University, Suzhou, Jiangsu, China. The proband was diagnosed by whole-exome sequencing. Peripheral blood samples were collected from EPM-11 patient and her parents. Clinical data included available medical histories, neuro-imaging, electroencephalogram and gene detection. The study followed the principles of the Declaration of Helsinki and was approved by the Institutional Review Committee of Children's Hospital Affiliated to Soochow University. Each participant provided written informed consent.

\section{Whole-exome sequencing}

Genomic DNA was extracted from peripheral blood samples. xGen Exome Research Panel v1.0 (IDT) was used to capture the target, according to the manufacturer's instructions, and an Illumina NovaSeq6000 (Illumina) sequenced the DNA. After the analysis and screening of the genetic disease precision diagnosis cloud platform system integrating molecular biology annotation, biology, genetics and clinical feature analysis, combined with information in the pathogenic mutation database, normal human genome database, and clinical feature database of 4,000 known genetic diseases, the genetic data analysis algorithm classifies hundreds of thousands of genetic mutations. The pathogenicity of the variation was evaluated according to ACMG guidelines. (Richards et al. 2015).

\section{Sanger Sequencing}

The candidate pathogenic genes identified by WES were confirmed by Sanger sequencing and cosegregation analyses among families. The PCR products were sequenced by ABI 3730XL DNA Sequencer (Applied Biosystems, Thermo Fisher Scientific, USA).

\section{Results \\ Clinical description}

The proband was the first child of a nonconsanguineous couple (G1P1) without birth history of asphyxia and hypoxia, but her mother had a history of pregnancy preservation due to reduced fetal movement. She was diagnosed with growth retardation at 10 months, and she could communicate simply (no more than 3 words), walk upright and run with a little difficulty at present after regular rehabilitation treatment. She presented with atonic seizures at 4 years 
old with low frequency and mild symptoms. After 6 years of age, the patients began to have recurrent seizures. Neurological examination demonstrated ataxia and intention tremor without any pathogenic reflex and increased deep tendon reflex. Electroencephalogram (EEG) showed pathogenic waves and brain magnetic resonance imaging (MRI) showed cerebellar tonsillar hernia (Fig. 1). Detailed clinical data are shown in Table 1.She was given sodium valproate to control seizures and responded well to this therapy. To date, she has had almost no relapse since follow-up. 
Table 1

Clinical features of the patient reported in this work and comparison with published cases with SEMA6B-related progressive myoclonic epilepsy(H

\begin{tabular}{|c|c|c|c|c|}
\hline Clinical data & $\begin{array}{l}\text { Kohei Hamanaka, et al. } \\
\text { (Individual 1) }\end{array}$ & $\begin{array}{l}\text { Kohei Hamanaka, et al. } \\
\text { (Individual 2) }\end{array}$ & $\begin{array}{l}\text { Kohei Hamanaka, et al. } \\
\text { (Individual 3) }\end{array}$ & $\begin{array}{l}\text { Kohei Hamanaka, et al. } \\
\text { (Individual 4) }\end{array}$ \\
\hline Country & Japanese & Japanese & Israeli & Malaysian \\
\hline Current age & 22 years & 28 years & 14 years & 11 years \\
\hline Sex & male & female & male & female \\
\hline Locus & SEMA6B & SEMA6B & SEMA6B & SEMA6B \\
\hline $\begin{array}{l}\text { Pathogenic } \\
\text { variant }\end{array}$ & $\begin{array}{l}\text { c.1950_1969dup(p.Arg657Profs³5) } \\
\text { de novo }\end{array}$ & $\begin{array}{l}\text { c.1976_1982del(p.Ala659Valfs*24) } \\
\text { de novo }\end{array}$ & $\begin{array}{l}\text { c.1991del(p.Gly664Alafs*21) } \\
\text { de novo }\end{array}$ & $\begin{array}{l}\text { c.1991del(p.Gly664Alafs*2 } \\
\text { de novo }\end{array}$ \\
\hline Age of onset & 6 years & 11 months & 2 years & 4 years \\
\hline $\begin{array}{l}\text { Initial } \\
\text { symptom }\end{array}$ & developmental delay and seizure & seizure & seizure & $\begin{array}{l}\text { developmental delay and } \\
\text { seizure }\end{array}$ \\
\hline $\begin{array}{l}\text { Developmental } \\
\text { history }\end{array}$ & $\begin{array}{l}\text { rolling over: } 12 \text { months; meaningful } \\
\text { words: } 24-36 \text { months; initial } \\
\text { walking without support: } 17 \\
\text { months. }\end{array}$ & $\begin{array}{l}\text { initial walking without support: } 28 \\
\text { months }\end{array}$ & $\begin{array}{l}\text { initial walking without } \\
\text { support: } 24 \text { months }\end{array}$ & $\begin{array}{l}\text { eye pursuit: } 5 \text { months; initia } \\
\text { walking without support: } 2 \text { ، } \\
\text { months; meaningful } \\
\text { words:30 months; }\end{array}$ \\
\hline $\begin{array}{l}\text { Intellectual } \\
\text { disability }\end{array}$ & severe (IQ = 25 at 17 years) & severe (IQ $=25$ at 12 years $)$ & severe & severe \\
\hline Microcephaly & $\mathrm{N}$ & $Y(-2.0 \mathrm{SD})$ & $Y(-2.5 S D)$ & $\mathrm{Y}(2$ nd percentile $)$ \\
\hline Regression & $\mathrm{Y}$ (motor skill and dysarthria) & Y (motor skill) & Y (motor and verbal skills) & $\mathrm{Y}$ \\
\hline $\begin{array}{l}\text { Seizure type at } \\
\text { onset }\end{array}$ & $\begin{array}{l}\text { GTCS since } 6 \text { years; absence } \\
\text { seizures since } 9 \text { years; atonic } \\
\text { seizures since } 11 \text { years }\end{array}$ & $\begin{array}{l}\text { GTCS since } 11 \text { months; loss of } \\
\text { consciousness with abnormal eye } \\
\text { movement since } 5 \text { years; complex } \\
\text { partial seizures since } 10 \text { years; } \\
\text { atonic seizures since } 10 \text { years }\end{array}$ & $\begin{array}{l}\text { absence seizures since } 2 \\
\text { years }\end{array}$ & atonic seizures since 4 yea \\
\hline $\begin{array}{l}\text { Response to } \\
\text { therapy } \\
\text { (antiepileptic } \\
\text { drugs) }\end{array}$ & intractable & intractable & responsive & $\begin{array}{l}\text { intractable, but improved b' } \\
\text { clobazam and sulthiame }\end{array}$ \\
\hline Ataxia & Y & Y & $\mathrm{Y}$ & $\mathrm{Y}$ \\
\hline $\begin{array}{l}\text { Intention } \\
\text { tremor }\end{array}$ & Y & Y & Y & Y \\
\hline Rigidity & Y & Y & NP & NP \\
\hline Myoclonus & Y & Y & NP & NP \\
\hline Spasticity & Y & $\mathrm{Y}$ & NP & NP \\
\hline $\begin{array}{l}\text { Increased deep } \\
\text { tendon reflex }\end{array}$ & Y (upper and lower limbs) & Y (upper and lower limbs) & NP & $\mathrm{N}$ \\
\hline $\begin{array}{l}\text { Pathogenic } \\
\text { reflex }\end{array}$ & $\begin{array}{l}\text { Y (Rossolimo sign: positive, Mendel- } \\
\text { Bechterew sign: positive) }\end{array}$ & $\mathrm{N}$ & NP & $\mathrm{N}$ \\
\hline $\begin{array}{l}\text { Dysmorphic } \\
\text { features }\end{array}$ & $\mathrm{N}$ & $\mathrm{N}$ & $\mathrm{N}$ & $\mathrm{N}$ \\
\hline $\begin{array}{l}\text { Motor } \\
\text { disturbance }\end{array}$ & wheelchair & wheelchair & wheelchair & walking with support \\
\hline Brain MRI & normal & mild cerebellar atrophy & small vermis & normal \\
\hline EEG & $\begin{array}{l}\text { abnormal discharge in right } \\
\text { hemisphere ( } 6 \text { years); burst of } \\
\text { diffuse irregular spikes and slow } \\
\text { waves ( } 9 \text { years); diffuse spike and } \\
\text { slow waves in frontal, parietal and } \\
\text { temporal regions ( } 14 \text { years) }\end{array}$ & $\begin{array}{l}\text { diffuse slow wave with } 2-3 \mathrm{~Hz} \\
\text { and spike-and-wave in bilateral } \\
\text { frontal region ( } 3 \text { years and } 4 \\
\text { years); diffuse theta waves with } 4- \\
5 \mathrm{~Hz} \text { and spike-and-wave burst } \\
\text { with } 2-3 \mathrm{~Hz} \text { ( } 9 \text { years); multifocal } \\
\text { spikes in left parietal region and } \\
\text { bilateral frontal regions (12 years); } \\
\text { multifocal in left occipital region } \\
\text { (13 years); slow waves at } \\
\text { baselines ( } 23 \text { years) }\end{array}$ & $\begin{array}{l}\text { abnormal background } \\
\text { activity ( } 1 \text { year); slow } \\
\text { abnormal sleep features with } \\
\text { a paucity of sleep spindles } \\
\text { (13 years). }\end{array}$ & $\begin{array}{l}\text { focal bifrontal epileptiform } \\
\text { discharges accentuated } \\
\text { during sleep ( } 4 \text { years); } \\
\text { frequent frontocentral } \\
\text { discharges during awake } \\
\text { state }(5 \text { years); frequent } \\
\text { intermittent slow spikes in } \\
\text { right posterior region ( } 11 \\
\text { years) }\end{array}$ \\
\hline SEP & $\begin{array}{l}\text { prolonged N20 latency and high } \\
\text { amplitude of P24-N33 }\end{array}$ & giant SEP & NP & NP \\
\hline
\end{tabular}




\begin{tabular}{|lllll}
\hline Clinical data & $\begin{array}{l}\text { Kohei Hamanaka, et al. } \\
\text { (Individual 1) }\end{array}$ & $\begin{array}{l}\text { Kohei Hamanaka, et al. } \\
\text { (Individual 2) }\end{array}$ & $\begin{array}{l}\text { Kohei Hamanaka, et al. } \\
\text { (Individual 3) }\end{array}$ & $\begin{array}{l}\text { Kohei Hamanaka, et al. } \\
\text { (Individual 4) }\end{array}$ \\
\hline Other findings & $\mathrm{NP}$ & $\mathrm{SLE}$ & $\mathrm{NP}$ & $\mathrm{NP}$ \\
\hline $\begin{array}{l}\text { Abbreviations: EEG, electroencephalogram; GTCS, generalized tonic-clonic seizures; MRI, magnetic resonance imaging; SEP, somatosensory evoked potential; } \\
\text { erythematosus; NP, not performed; U, unknown; Y, present; and N, not present. }\end{array}$
\end{tabular}

\section{Mutation analysis}

A Variant in SEMA6B (NM_032108.4), c.1960_ 1978del/p.Leu654Argfs*25 (Fig. 2), was identified by whole exome-sequencing in this patient. The variant was found to be a de novo variant. The variant is classified as "pathogenic" following ACMG guidelines (Richards et al. 2015), which has not been reported in the literature. The variant is located in the last exon of SEMA6B.

\section{Discussion}

The SEMA6B gene contains 17 coding exons and a PPAR-binding site in the upstream sequence, and it is located on chromosome 19p13 (Correa et al. 2001). Through the use of immunostaining, Hamanaka et al localized the expression of the SEMA6B gene to neurons in multiple brain regions, including the cerebral cortex, cerebellar Purkinje cells and interneurons; specific cell types included excitatory and GABAergic inhibitory neurons (Hamanaka et al. 2020). SEMA6B is a member of the class- 6 semaphorin family, which is involved in different aspects of neural development, including neural crest cell migration, axon guidance and cerebellar development (Andermatt et al. 2014). For example, Sema6B and Sema6A interact with PLXNA2 and plxna4 in axonal guidance in the regulation of mossy fiber targeting in the hippocampus (Suto et al. 2007; Tawarayama et al. 2010). Irwin Andermatt et al found that Sema6B mediated the outgrowth response of commissural neurons by interacting with PIxnA2, and played a role as a receptor in commissural axons. The absence of SEMA6B can lead to defects in the guidance of commissural axons (Andermatt et al. 2014). To date, mutations in the last exon of the SEMA6B gene have been reported in four patients from four independent families. These mutations are predicted to escape nonsense-mediated mRNA decay and lead to truncated proteins lacking intracellular domains (Hamanaka et al. 2020). At present only a few patient/pathogenic variants have been reported, and this neurodegenerative disease caused by de novo heterozygous frameshift mutations in the last exon of the SEMA6B gene is a relatively new disease-gene relationship. We carried out gene curation following the GlinGen gene curation protocol. According to this Chinese family and the previously published cases, the total score of clinical validity is 12.5 (10 points for genetic evidence and 2.5 points for experimental evidence); therefore, there is enough evidence to support the "strong" gene-disease relationship. We reported the fifth case of a de novo heterozygous frameshift mutation in the last exon of the SEMA6B gene. Our patient is the first case in China, and this report plays an important role in extending the mutational spectrum.

Truncating variants in other regions of the SEMA6B gene were found in the gnomAD database, but in the last exon of the SEMA6B gene. Based on RNA analysis of lymphoblasts from a patient and experimental studies from animal model organisms, Hamanaka et al speculated that these variants would lead to dominant-negative or gain-of-function effects rather than haploid deficiency (Hamanaka et al. 2020). However the variant of our patient was thought to be a loss-of-function variant in the NMD(-) region, which was located in the last 50 bp of the penultimate exon or in the last exon of the SEMA6B gene. The variant was observed to be de novo without any family history of EPM-11 (the patient's biological parents' samples tested negative), and the phenotype of our patient also matched the clinical manifestations of EPM-11. PVS1 and PS2 should be strongly pathogenic in accordance with ACMG guidelines (Richards et al. 2015), and the minor allele frequency (MAF) was less than 0.0005 ; thus, the mutation incidence in this disease is expected to be rare and provids moderate evidence that it is a pathogenic mutation in EPM-11. Pathogenic variants related to EPM-11 were concentrated in exon 17 of SEMA6B, which was consistent with the distribution of pathogenic variants detected in our patients, indicating that exon 17 of SEMA6B is more clinically relevant.

The clinical presentations of all reported patients are summarized in Table 1. The manifestations are mainly characterized by common symptoms including developmental delay, seizures, intellectual disability, motor disturbance, ataxia, intention tremor, myoclonus and abnormal EEG and possible symptoms such as microcephaly, rigidity, spasticity, increased deep tendon reflex, cerebellar atrophy, positive pathogenic reflexes, and cerebellar atrophy in brain MRI (Hamanaka et al. 2020). The condition of our patient was basically consistent with these common clinical features, Moreover, her brain MRI demonstrated cerebellar tonsils herniation rather than cerebellar atrophy. We may obtain more complete understanding of this disease via the study of these rare cases, which could also help in the differential diagnosis of EPM-11.

\section{Conclusions}

We reported the first EPM-11 case with a de novo heterozygous frameshift mutation in China. The new genetic evidence we reported here strengthened the gene-disease relationship, because the gene curation level between SEMA6B and EPM-11 became "strong" following ClinGen SOP. This finding revealed the role of new mutations as important genetic causes of EPM-11 and broadened the molecular genetic basis of EPM-11.

\section{Abbreviations}

SEMA6B: semaphorin 6B

MRI: magnetic resonance imaging

EPM: progressive myoclonic epilepsy 
EEG: electroencephalogram

\section{Declarations}

ETHICAL STATEMENT:

\section{Ethics approval and consent to participate}

The study was based on the principles of the Declaration of Helsinki and authorized by the Institutional Review Committee of Children's Hospital Affiliated to Soochow University. Written consent for publication was obtained from the patient.

\section{Competing interests}

The authors declare that they have no conflicts of interest.

\section{Data availability}

The data and material discussed here are available in the references listed.

\section{Consent for publication:}

All participants signed written informed consent forms.

\section{Funding}

This study was supported by grants from Jiangsu Provincial Key Research and Development Program (No.BE2018661), The Fifteenth Batch of Jiangsu Province Funds for Selection and Training of High-level Talents (WSN-028) and Suzhou Science and Technology Development Program (SYSD2020122).

\section{Authors contributors}

LQ and LM drafted the manuscript and contributed to conception and design of the study. HDP, JP, and LWH cared for the patient and critically revised the article. HJ and LT contributed to the data acquisition. CXQ critically revised and gave final approval for publication of the paper.

\section{Acknowledgements}

We thank the patient, her family members for their cooperation and contribution.

\section{References}

1. Andermatt I, Wilson NH, Bergmann T et al (2014) Semaphorin 6B acts as a receptor in post-crossing commissural axon guidance. Development 141(19):3709-3720

2. Correa RG, Sasahara RM, Bengtson MH et al (2001) Human semaphorin 6B [(HSA)SEMA6B], a novel human class 6 semaphorin gene: alternative splicing and all-trans-retinoic acid-dependent downregulation in glioblastoma cell lines. Genomics 73(3):343-348

3. Dijk JM, Tijssen MA (2010) Management of patients with myoclonus: available therapies and the need for an evidence-based approach. Lancet Neurol 9(10):1028-1036

4. Franceschetti S, Michelucci R, Canafoglia L et al (2014) Progressive myoclonic epilepsies: definitive and still undetermined causes. Neurology 82(5):405411

5. Hamanaka K, Imagawa E, Koshimizu E et al (2020) De Novo Truncating Variants in the Last Exon of SEMA6B Cause Progressive Myoclonic Epilepsy. Am J Hum Genet 106(4):549-558

6. Holmes GL (2020) Drug Treatment of Progressive Myoclonic Epilepsy. Paediatr Drugs 22(2):149-164

7. Kälviäinen R (2015) Progressive Myoclonus Epilepsies. Semin Neurol 35(3):293-299

8. Malek N, Stewart W, Greene J (2015) The progressive myoclonic epilepsies. Pract Neurol 15(3):164-171

9. Richards S, Aziz N, Bale S et al (2015) Standards and guidelines for the interpretation of sequence variants: a joint consensus recommendation of the American College of Medical Genetics and Genomics and the Association for Molecular Pathology. Genet Med 17(5):405-424

10. Satishchandra P, Sinha S (2010) Progressive myoclonic epilepsy. Neurol India 58(4):514-522

11. Suto F, Tsuboi M, Kamiya $\mathrm{H}$ et al (2007) Interactions between plexin-A2, plexin-A4, and semaphorin $6 \mathrm{~A}$ control lamina-restricted projection of hippocampal mossy fibers. Neuron 53(4):535-547

12. Tawarayama H, Yoshida Y, Suto F, Mitchell KJ, Fujisawa H (2010) Roles of semaphorin-6B and plexin-A2 in lamina-restricted projection of hippocampal mossy fibers. J Neurosci 30(20):7049-7060

\section{Figures}



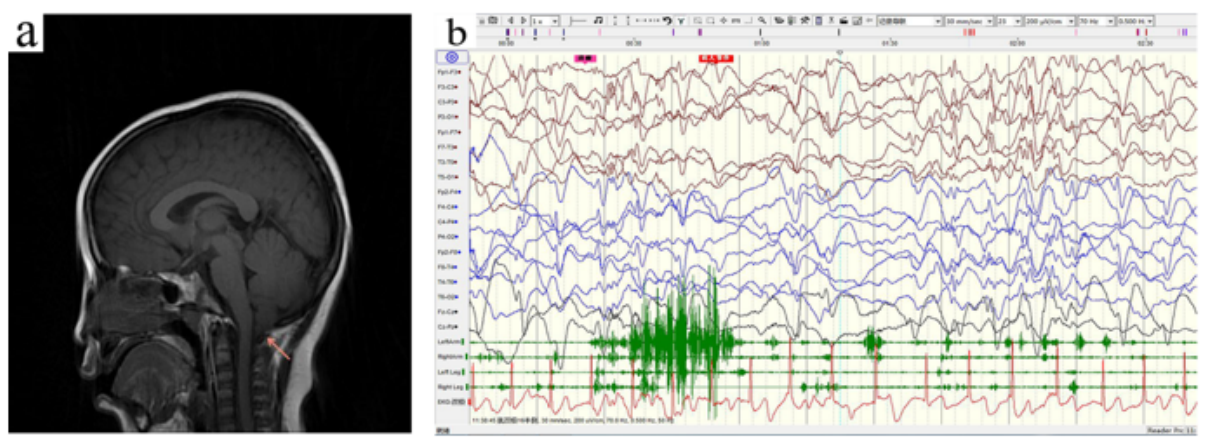

\section{Figure 1}

Brain magnetic resonance imaging (MRI) and electroencephalogram (EEG) in this case. a: Brain MRI findings (sagittal; T1-weighted image) of this case. Cerebellar tonsillar hernia was seen as indicated by the arrow. b: EEG in this case. diffuse spike-and-wave burst with $1.5-2.5 \mathrm{~Hz}$ in the attack, especially in frontal regions; temporary increase in myoelectric activity; interictal widespread slow-spina wave with $1.5-2.0 \mathrm{~Hz}$ released continuously and irregularly.

c.1960_c.1978delCTGGGCGAGCGCAGGGCGC

Standard sequence T G A G C G T C A GC C GC C T G G G G A G C GCA G G C G A G G T C C C G G G G G C

$\downarrow$

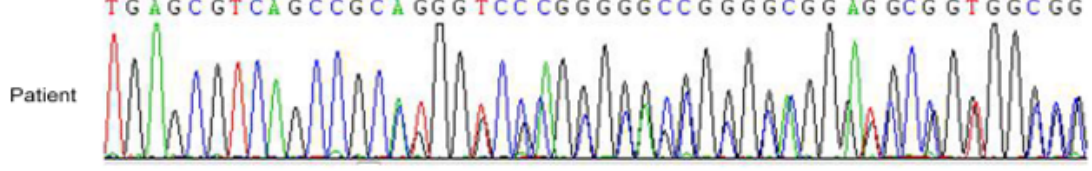

TGAGCGTCAGCCGCCTGGGCGAGCGCAGGGCGCAGGGTCCCGGGGGCC

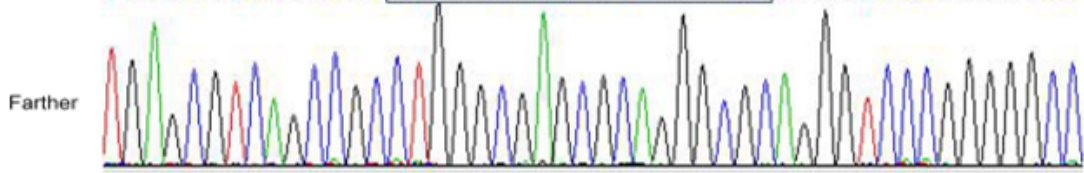

TGAGCGTCAGCCGCCTGGGCGAGCGCAGGGCGCAGGGTCCCGGGGGCC

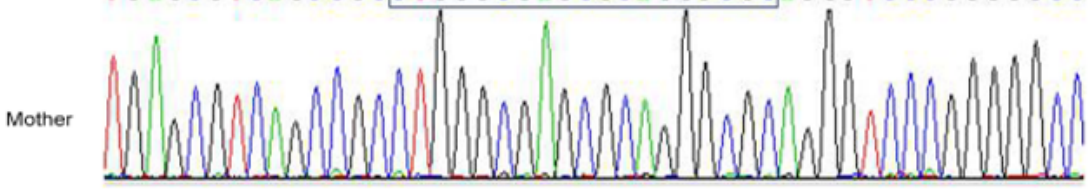

\section{Figure 2}

Sequence chromatograms of the denovo variant of our patient. Variant is indicated by red arrows. 